\title{
Temperature Dependence of Initiation Reactions of Oxygen-Centered Radicals
}

\author{
Yasumasa Watanabe, ${ }^{\dagger}$ Hideyo Ishigaki, Hiroshi Okada, and Shuji SuYama \\ Fine Chemicals \& Polymers Research Laboratory, NOF Corporation, \\ Taketoyo-cho, Chita-gun, Aichi 470-23, Japan
}

(Received February 5, 1997)

\begin{abstract}
The temperature dependence of initiation reactions of $t$-butoxy, cumyloxy, and benzoyloxy radicals, was studied using 2,4-diphenyl-4-methyl-1-pentene ( $\alpha$-methylstyrene dimer, MSD) as a model compound of styrene and a radical trapping agent. The ratios between addition of the oxy radicals to MSD and their self-decomposition ( $\beta$-scission or decarboxylation) were found to greatly depend on the reaction temperature. The differences in activation energy between self-decomposition and addition $\left(E_{\mathrm{d}}-E_{\mathrm{a}}\right)$ for $t$-butoxy, cumyloxy, and bezoyloxy radicals were estimated to be 7.8, 7.9, and $5.0 \mathrm{kcal} \mathrm{mol}^{-1}$, respectively. End group ratios ( $t$-butoxy/methyl, cumyloxy/methyl, and benzoyloxy/phenyl) for polystyrene obtained by initiation of the oxy radicals are simulated over the temperature range $50-150^{\circ} \mathrm{C}$.

KEY WORDS Oxygen-centered Radicals / Initiation Reactions / Temperature Dependence / End Groups / $\alpha$-Methylstyrene Dimer /
\end{abstract}

Most commercial vinyl polymers such as polystyrene (PS), polyethylene, and poly(vinyl chloride) are produced by free radical polymerization, where organic peroxides are used as main free radical initiators. Organic peroxides decompose thermally by homolytic cleavage of $\mathrm{O}-\mathrm{O}$ bond to give free radicals which initiate the polymerization of vinyl monomers. Thus, initiating radicals from organic peroxides are necessarily incorporated into polymer structure as end groups. Since such end groups are dependent on peroxide structure and have profound influence on polymer properties such as thermal and light stability, it is quite important to clarify the initiation mechanisms of organic peroxides, in particular, for commercially useful peroxides.

Recently, we have developed a new method for investigating the initiation mechanisms of organic peroxides using 2,4-diphenyl-4-methyl-1-pentene ( $\alpha$-methylstyrene dimer, MSD) as a radical trapping agent. ${ }^{1,2}$ This original technique (MSD trapping technique) is based on a unique radical chemistry of MSD, that is, addition-fragmentation reaction between free radicals and MSD (eq 1 and 2). ${ }^{3}$ The easy deactivation of cumyl radicals by selfreactions (eq 3) also contributes to this success.
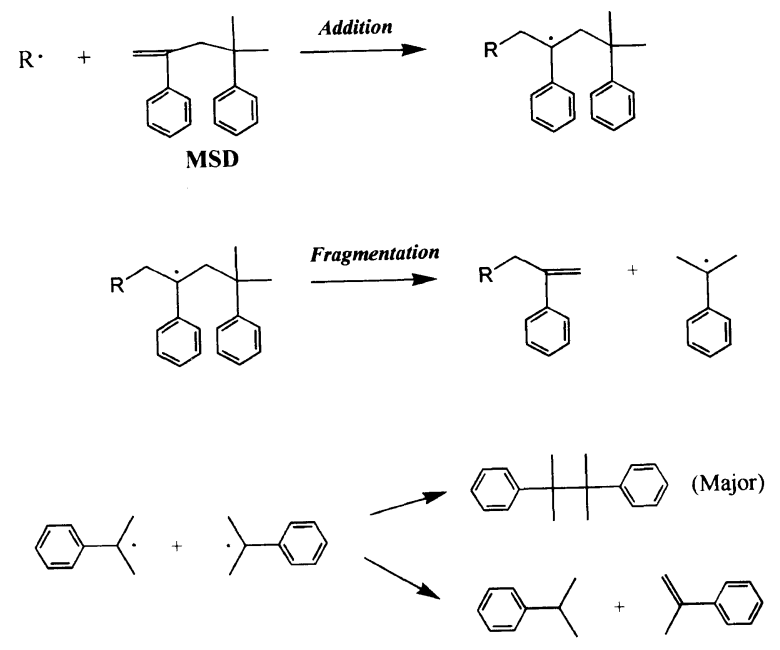

The outline of MSD trapping technique is depicted in Scheme 1. When organic peroxides decompose in MSD,

\footnotetext{
† To whom all correspondence should be addressed.
}

stable olefinic compounds (1) having various fragments (X) derived from organic peroxides are produced through addition-fragmentation reaction. By analyzing these trapping products (1), we can obtain useful information on the free radical chemistry of organic peroxides. We

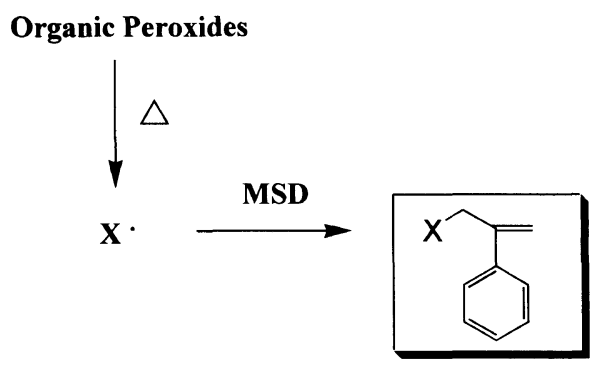

(1)

Scheme 1. Outline of MSD trapping.

have demonstrated that the double bond reactivity of MSD is about the same as that of styrene (St). ${ }^{1,2}$ Therefore, the trapping products are closely related to initiating radicals in St polymerization. For example, we presented the initiation mechanisms of dialkyl peroxides ${ }^{1}$ and peresters ${ }^{2}$ at $140^{\circ} \mathrm{C}$. The reactions of alkoxy and benzoyloxy radicals generated from the peroxides are summarized in Scheme 2. The main reactions of these oxygen-centered radicals (oxy radicals) are direct addition and decomposition ( $\beta$-scission or decarboxylation). The ratios normalized to $100 \%$ are also listed in Scheme 2.

In the previous study, ${ }^{1}$ hydrogen abstraction from MSD was observed in the case of $t$-butoxy radicals $(20 \%)$. However, this side reaction does not influence the addition $/ \beta$-scission ratio since the three reactions (addition, $\beta$-scission, and hydrogen abstraction) occur competitively from common $t$-butoxy radicals. It is well known that no hydrogen abstraction reaction occurs between $t$-butoxy radicals and styrene. Therefore, we require only the addition $/ \beta$-scission value in order to estimate the initiation reaction of $t$-butoxy radicals with styrene from the model reaction with MSD.

Free-radical St polymerization is performed at various temperatures (e.g., $\left.50-150^{\circ} \mathrm{C}\right)$ depending on desired polymerization rates and polymer molecular weights. 

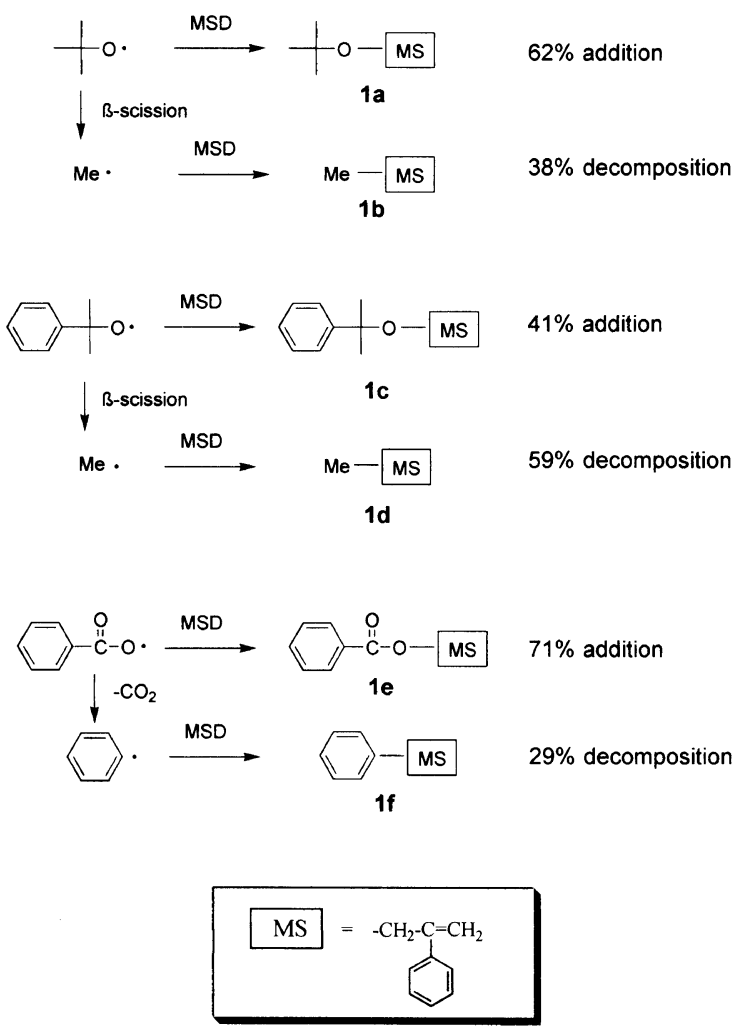

Scheme 2. Reactions of oxygen-centered radicals in MSD at $140^{\circ} \mathrm{C}$.

Therefore, information on the end group structure at any temperature is highly valuable and desirable. This paper describes the temperature dependence of initiation reactions of $t$-butoxy $(t-\mathrm{BuO} \cdot)$, cumyloxy $(\mathrm{CuO} \cdot)$, and benzoyloxy radicals ( $\mathrm{PhCOO} \cdot)$ using $\mathrm{MSD}$ trapping technique. Using activation parameters determined, PS end group ratios $(t-\mathrm{BuO} /$ methyl $(\mathrm{Me}), \mathrm{CuO} / \mathrm{Me}$, and $\mathrm{PhCOO} / \mathrm{Ph}$ ) in bulk styrene polymerization are simulated over the temperature range $50-150^{\circ} \mathrm{C}$.

\section{EXPERIMENTAL}

\section{Measurements}

GLC analyses were performed with Shimadzu GC-14A and GC-17A gas chromatographs with a flame ionization detector using capillary columns $(15 \mathrm{~m} \times 0.53 \mathrm{~mm}$ or $25 \mathrm{~m} \times 0.25 \mathrm{~mm}$ ). GC-MS analyses were conducted on a Shimadzu QP5000 under electron impact conditions $(70 \mathrm{eV})$.

\section{Materials}

2,4-Diphenyl-4-methyl-1-pentene (MSD) was obtained from NOF Corporation (Nofmer MSD) and used after purifying by distillation. Organic peroxides were obtained from NOF Corporation and used as received. $O O$ - $t$-Butyl $O$-isopropyl peroxycarbonate (BuI), $t$-butyl peroxybenzoate $(\mathrm{BuZ})$, and di-t-butyl peroxide $(\mathrm{BuD})$ were used as precursors of $t$ - $\mathrm{BuO} \cdot$. Dicumyl peroxide (DCP) was used as a precursor of $\mathrm{CuO} \cdot \mathrm{BuZ}$ and $t$-hexyl peroxybenzoate (HexZ) were used as precursors of $\mathrm{PhCOO}$.

\section{MSD Trapping Experiments}

An aliquot $(2 \mathrm{ml})$ of $0.02 \mathrm{M}$ solution of organic peroxides in MSD was charged into a glass ampoule.
The ampoule was purged with nitrogen, sealed, and immersed in a constant temperature bath regulated at given temperature. Trapping products $1 \mathbf{a}-\mathbf{- 1 f}$ were characterized by GLC and GC-MS. The analytical data were described previously. ${ }^{1,2}$ Yields of $\mathbf{1 a}-\mathbf{1 f}$ were determined by GLC.

\section{RESULTS}

Reactions of $t-B u O$.

Organic peroxides with $t$ - $\mathrm{BuO}$ group were decomposed in MSD at $120-150^{\circ} \mathrm{C}$ up to $>99.9 \%$ decomposition. The yields of 1a (addition) and $\mathbf{1 b}$ (decomposition) were determined by GLC. The yield ratios of $\mathbf{1 a}$ and $\mathbf{1 b}$ are shown in Table I. The results obtained with different precursors agreed very well with one another at the same temperature. The proportion of $\mathbf{1 b}$ increased with temperature, indicating that the activation energy of $\beta$ scission of $t$ - $\mathrm{BuO} \cdot$ is higher than that of its addition to MSD.

The ratios of the addition rate constant $\left(k_{\mathrm{a}}\right)$ to the decomposition rate constant $\left(k_{\mathrm{d}}\right)$ were calculated using the average yield ratios of $\mathbf{1 a}$ to $\mathbf{1 b}$ and the initial MSD concentration $(4.15 \mathrm{M})$ according to the equation of $k_{\mathrm{a}} / k_{\mathrm{d}}=[1 \mathbf{a}] / 4.15[1 \mathbf{b}]$. The Arrhenius plot $\left(\ln k_{\mathrm{a}} / k_{\mathrm{d}} v s\right.$. $1 / T)$ gave a good straight line with a correlation coefficient $r=0.999$. From the intercept and slope of the plot, activation parameters $\left(A_{\mathrm{a}} / A_{\mathrm{d}}\right.$ and $\left.E_{\mathrm{d}}-E_{\mathrm{a}}\right)$ were determined (Table II) . It was found that the activation energy of $\beta$-scission of $t$-BuO is $\sim 8 \mathrm{kcal} \mathrm{mol}^{-1}$ higher than that of its addition to MSD.

\section{Reactions of $\mathrm{CuO}$.}

DCP was decomposed in MSD at $130-150^{\circ} \mathrm{C}$. The

Table I. Effect of temperature on reaction of $t-\mathrm{BuO} \cdot$ in $\mathrm{MSD}^{\mathrm{a}}$

\begin{tabular}{ccr}
\hline Precursor $^{\mathrm{b}}$ & Temp $^{\circ} \mathrm{C}$ & {$[\mathbf{1 a}] /[\mathbf{1} \mathbf{b}]^{\mathrm{c}}$} \\
\hline BuI & 120 & $70.5 / 29.5$ \\
BuZ & 120 & $73.0 / 27.0$ \\
& & Ave. $71.7 / 28.3$ \\
\hline BuI & 130 & $66.4 / 33.6$ \\
BuZ & 130 & $66.9 / 33.1$ \\
& & Ave. $66.6 / 33.4$ \\
BuD & 140 & $61.9 / 38.1$ \\
BuI & 140 & $59.4 / 40.6$ \\
BuZ & 140 & $60.6 / 39.4$ \\
& & Ave. $60.6 / 39.4$ \\
BuD & 150 & $55.4 / 44.6$ \\
BuZ & 150 & $56.1 / 43.9$ \\
& & Ave. $55.7 / 44.3$ \\
\hline
\end{tabular}

${ }^{\mathrm{a}}[\mathrm{MSD}]=4.15 \mathrm{M} .{ }^{\mathrm{b}}[$ Precursor $]=0.02 \mathrm{M} .{ }^{\mathrm{c}}$ Addition $/ \mathrm{decom}-$ position ( $\beta$-scission).

Table II. Activation parameters for reaction of $t$-BuO .

\begin{tabular}{|c|c|c|c|}
\hline \multirow{2}{*}{$\frac{\text { Temp }}{{ }^{\circ} \mathrm{C}}$} & \multirow{2}{*}{$\frac{k_{\mathrm{a}} / k_{\mathrm{d}}}{\mathrm{M}^{-1}}$} & \multicolumn{2}{|c|}{ Activation parameters ${ }^{\mathrm{a}}$} \\
\hline & & $A_{\mathrm{a}} / A_{\mathrm{d}} / \mathrm{M}^{-1}$ & $E_{\mathrm{d}}-E_{\mathrm{a}} / \mathrm{kcal} \mathrm{mol}^{-1}$ \\
\hline 120 & 0.610 & $3.04 \times 10^{-5}$ & 7.77 \\
\hline 130 & 0.480 & & \\
\hline 140 & 0.371 & & \\
\hline 150 & 0.303 & & \\
\hline
\end{tabular}

${ }^{\text {a }}$ Correlation coefficient of Arrhenius plot, 0.999 . 
Table III. Effect of temperature on reaction of $\mathrm{CuO} \cdot$ in $\mathrm{MSD}^{\mathrm{a}}$

\begin{tabular}{ccc}
\hline Precursor $^{\mathrm{b}}$ & Temp $/{ }^{\circ} \mathrm{C}$ & {$[\mathbf{1 c}] /[\mathbf{1 d}]^{\mathrm{c}}$} \\
\hline DCP & 130 & $48.8 / 51.2$ \\
DCP & 140 & $40.8 / 59.2$ \\
DCP & 150 & $37.3 / 62.7$ \\
\hline
\end{tabular}

${ }^{\mathrm{a}}[\mathrm{MSD}]=4.15 \mathrm{M} .{ }^{\mathrm{b}}[$ Precursor $]=0.02 \mathrm{M} . \quad{ }^{\mathrm{c}}$ Addition $/ \mathrm{decom}-$ position ( $\beta$-scission).

Table IV. Activation parameters for reaction of $\mathrm{CuO}$.

\begin{tabular}{|c|c|c|c|}
\hline \multirow{2}{*}{$\frac{\text { Temp }}{{ }^{\circ} \mathrm{C}}$} & \multirow{2}{*}{$\frac{k_{\mathrm{a}} / k_{\mathrm{d}}}{\mathbf{M}^{-1}}$} & \multicolumn{2}{|c|}{ Activation parameters ${ }^{a}$} \\
\hline & & $A_{\mathrm{a}} / A_{\mathrm{d}} / \mathrm{M}^{-1}$ & $E_{\mathrm{d}}-E_{\mathrm{a}} / \mathrm{kcal} \mathrm{mol}^{-1}$ \\
\hline 130 & 0.230 & $1.10 \times 10^{-5}$ & 7.94 \\
\hline 140 & 0.167 & & \\
\hline 150 & 0.143 & & \\
\hline
\end{tabular}

${ }^{a}$ Correlation coefficient of Arrhenius plot, 0.982 .

Table V. Effect of temperature on reaction of $\mathrm{PhCOO} \cdot$ in $\mathrm{MSD}^{\mathrm{a}}$

\begin{tabular}{ccc}
\hline Precursor $^{\mathbf{b}}$ & Temp $/{ }^{\circ} \mathrm{C}$ & {$[\mathbf{1 e}] /[\mathbf{1 f}]^{\mathbf{c}}$} \\
\hline BuZ & 120 & $75.0 / 25.0$ \\
HexZ & 120 & $75.0 / 25.0$ \\
& & Ave. $75.0 / 25.0$ \\
\hline BuZ & 130 & $73.3 / 26.7$ \\
HexZ & 130 & $71.7 / 28.3$ \\
& & Ave. $72.5 / 27.5$ \\
\hline BuZ & 140 & $70.9 / 29.1$ \\
HexZ & 140 & $70.2 / 29.8$ \\
& & Ave. $70.5 / 29.5$ \\
\hline BuZ & 150 & $65.2 / 34.8$
\end{tabular}

${ }^{\mathrm{a}}[\mathrm{MSD}]=4.15 \mathrm{M} .{ }^{\mathrm{b}}[$ Precursor $]=0.02 \mathrm{M} . \quad{ }^{\mathrm{c}}$ Addition $/ \mathrm{decom}-$ position (decarboxylation).

Table VI. Activation parameters for reaction of $\mathrm{PhCOO}$.

\begin{tabular}{|c|c|c|c|}
\hline \multirow{2}{*}{$\frac{\text { Temp }}{{ }^{\circ} \mathrm{C}}$} & \multirow{2}{*}{$\frac{k_{\mathrm{a}} / k_{\mathrm{d}}}{\mathrm{M}^{-1}}$} & \multicolumn{2}{|c|}{ Activation parameters ${ }^{\mathbf{a}}$} \\
\hline & & $A_{\mathrm{a}} / A_{\mathrm{d}} / \mathrm{M}^{-1}$ & $E_{\mathrm{d}}-E_{\mathrm{a}} / \mathrm{kcal} \mathrm{mol}^{-1}$ \\
\hline 120 & 0.723 & $1.21 \times 10^{-3}$ & 5.01 \\
\hline 130 & 0.635 & & \\
\hline 140 & 0.576 & & \\
\hline 150 & 0.451 & & \\
\hline
\end{tabular}

${ }^{a}$ Correlation coefficient of Arrhenius plot, 0.980 .

yield ratios of 1c (addition) and 1d (decomposition) are shown in Table III. The $k_{\mathrm{a}} / k_{\mathrm{d}}$ ratios and activation parameters determined by the Arrhenius plot $(r=0.982)$ are shown in Table IV. The activation energy of $\beta$-scission of $\mathrm{CuO} \cdot$ was estimated to be $\sim 8 \mathrm{kcal} \mathrm{mol}^{-1}$ higher than that of its addition to MSD. The value was almost the same as that of $t-\mathrm{BuO}$.

\section{Reactions of PhCOO.}

$\mathrm{BuZ}$ and HexZ were decomposed in MSD at $120-150^{\circ} \mathrm{C}$. The yield ratios of $1 \mathrm{e}$ (addition) and $\mathbf{1 f}$ (decomposition) are shown in Table $\mathrm{V}$. The $k_{\mathrm{a}} / k_{\mathrm{d}}$ ratios and activation parameters determined by the Arrhenius plot $(r=0.980)$ are shown in Table VI. The activation
Table VII. Prediction of PS end group ratios of $t-\mathrm{BuO} / \mathrm{Me}^{\mathrm{a}}$

\begin{tabular}{|c|c|c|c|}
\hline Temp & $k_{\mathrm{a}} / k_{\mathrm{d}}^{\mathrm{b}}$ & Initial ratio $^{c}$ & Overall ratio $^{d}$ \\
\hline${ }^{\circ} \mathrm{C}$ & $M^{-1}$ & $t-\mathrm{BuO} / \mathrm{Me}$ & $t-\mathrm{BuO} / \mathrm{Me}$ \\
\hline 50 & 5.54 & $98 / 2$ & $96 / 4$ \\
\hline 60 & 3.85 & $97 / 3 \quad(99 / 1)^{\mathrm{e}}$ & $94 / 6$ \\
\hline 70 & 2.73 & $96 / 4$ & $92 / 8$ \\
\hline 80 & 1.98 & $95 / 5 \quad(96 / 4)^{f}$ & $90 / 10$ \\
\hline 90 & 1.46 & $93 / 7$ & $86 / 14$ \\
\hline 100 & 1.09 & $91 / 9$ & $83 / 17$ \\
\hline 110 & 0.830 & $88 / 12$ & $78 / 22$ \\
\hline 120 & 0.640 & $85 / 15$ & $74 / 26$ \\
\hline 130 & 0.500 & $81 / 19(85 / 15)^{f}$ & $69 / 31$ \\
\hline 140 & 0.395 & $78 / 22$ & $63 / 37$ \\
\hline 150 & 0.316 & $73 / 27$ & $58 / 42$ \\
\hline
\end{tabular}

${ }^{a}$ For bulk styrene polymerization. ${ }^{b}$ Calculated from activation parameters (see Table II). ${ }^{\mathrm{c}}$ Ratios for PS obtained initially (calculated as $[\mathrm{St}]=8.7 \mathrm{M}$ ). ${ }^{\mathrm{d}}$ Ratios for PS obtained finally (calculated as $[\mathrm{St}]=4.35 \mathrm{M})$. ${ }^{\mathrm{e}}$ Calculated using data from ref $5 .{ }^{\mathrm{f}}$ Calculated using data from ref 8 .

Table VIII. Prediction of PS end group ratios of $\mathrm{CuO} / \mathrm{Me}^{\mathrm{a}}$

\begin{tabular}{|c|c|c|c|}
\hline Temp & $k_{\mathrm{a}} / k_{\mathrm{d}}{ }^{\mathrm{b}}$ & Initial ratio $^{c}$ & Overall ratio $^{d}$ \\
\hline${ }^{\circ} \mathrm{C}$ & $\mathbf{M}^{-1}$ & $\mathrm{CuO} / \mathrm{Me}$ & $\mathrm{CuO} / \mathrm{Me}$ \\
\hline 50 & 2.61 & $96 / 4$ & $92 / 8$ \\
\hline 60 & 1.80 & $94 / 6 \quad(94 / 6)^{\mathrm{e}}$ & $89 / 11$ \\
\hline 70 & 1.27 & $92 / 8$ & $85 / 15$ \\
\hline 80 & 0.912 & $89 / 11$ & $80 / 20$ \\
\hline 90 & 0.668 & $85 / 15$ & $74 / 26$ \\
\hline 100 & 0.497 & $81 / 19$ & $68 / 32$ \\
\hline 110 & 0.376 & $77 / 23$ & $62 / 38$ \\
\hline 120 & 0.288 & $71 / 29$ & $56 / 44$ \\
\hline 130 & 0.224 & $66 / 34$ & $49 / 51$ \\
\hline 140 & 0.176 & $60 / 40$ & $43 / 57$ \\
\hline 150 & 0.140 & $55 / 45$ & $38 / 62$ \\
\hline
\end{tabular}

${ }^{a}$ For bulk styrene polymerization. ${ }^{\mathrm{b}}$ Calculated from activation parameters (see Table IV). ${ }^{\mathrm{c}}$ Ratios for PS obtained initially (calculated as $[\mathrm{St}]=8.7 \mathrm{M}$ ). ${ }^{\mathrm{d}}$ Ratios for PS obtained finally (calculated as $[\mathrm{St}]=4.35 \mathrm{M})$. $\quad{ }^{\mathrm{e}}$ Calculated using data from ref 6 .

energy of decarboxylation of $\mathrm{PhCOO}$ - was estimated to be $\sim 5 \mathrm{kcal} \mathrm{mol}^{-1}$ higher than that of its addition to MSD. The value was somewhat smaller than those of $\beta$-scission of alkoxy radicals $(t-\mathrm{BuO} \cdot$ and $\mathrm{CuO} \cdot)$.

\section{DISCUSSION}

It is possible to extrapolate $k_{\mathrm{a}} / k_{\mathrm{d}}$ values to any temperature using activation parameters obtained in this study. For example, the $k_{\mathrm{a}} / k_{\mathrm{d}}$ values for each oxy radical were calculated in the temperature range $50-150^{\circ} \mathrm{C}$ (Tables VII-IX). Since the rate constant for addition of oxy radicals to the styrenic double bond of MSD is considered to be about the same as that for their addition to St as demonstrated by previous studies, ${ }^{1,2}$ the calculated $k_{\mathrm{a}} / k_{\mathrm{d}}$ values are useful for prediction of end group structures of PS obtained by initiation of the oxy radicals. As typical examples, we estimated the end group ratios of $t-\mathrm{BuO} / \mathrm{Me}, \mathrm{CuO} / \mathrm{Me}$, and $\mathrm{PhCOO} / \mathrm{Ph}$ for $\mathrm{PS}$ produced initially (initial ratio) and finally (overall ratio) during bulk St polymerization (Tables VII-IX). The temperature dependence of overall ratios is depicted in Figures 
Table IX. Prediction of PS end group ratios of $\mathrm{PhCOO} / \mathrm{Ph}^{\mathrm{a}}$

\begin{tabular}{|c|c|c|c|}
\hline Temp & $k_{\mathrm{a}} / k_{\mathrm{d}}^{\mathrm{b}}$ & Initial ratio $^{c}$ & Overall ratio $^{d}$ \\
\hline${ }^{\circ} \mathrm{C}$ & $\mathbf{M}^{-1}$ & $\mathrm{PhCOO} / \mathrm{Ph}$ & $\mathrm{PhCOO} / \mathrm{Ph}$ \\
\hline 50 & 2.98 & $96 / 4$ & $93 / 7$ \\
\hline 60 & 2.36 & $95 / 5(95 / 5)^{\mathrm{e}}$ & $91 / 9$ \\
\hline 70 & 1.89 & $94 / 6$ & $89 / 11$ \\
\hline 80 & 1.54 & $93 / 7(93 / 7)^{\mathrm{f}}$ & $87 / 13$ \\
\hline 90 & 1.26 & $92 / 8$ & $85 / 15$ \\
\hline 100 & 1.05 & $90 / 10$ & $82 / 18$ \\
\hline 110 & 0.878 & $88 / 12$ & $79 / 21$ \\
\hline 120 & 0.742 & $87 / 13$ & $76 / 24$ \\
\hline 130 & 0.633 & $85 / 15$ & $73 / 27$ \\
\hline 140 & 0.544 & $83 / 17$ & $70 / 30$ \\
\hline 150 & 0.471 & $80 / 20$ & $67 / 33$ \\
\hline
\end{tabular}

${ }^{a}$ For bulk styrene polymerization. ${ }^{\mathrm{b}}$ Calculated from activation parameters (see Table VI). ${ }^{\mathrm{c}}$ Ratios for PS obtained initially (calculated as $[\mathrm{St}]=8.7 \mathrm{M}$ ). ${ }^{\mathrm{d}}$ Ratios for PS obtained finally (calculated as $[\mathrm{St}]=4.35 \mathrm{M})$. ${ }^{\mathrm{e}}$ Calculated using data from ref $7 .{ }^{\mathrm{f}} \mathrm{Cal}-$ culated using data from ref 9.

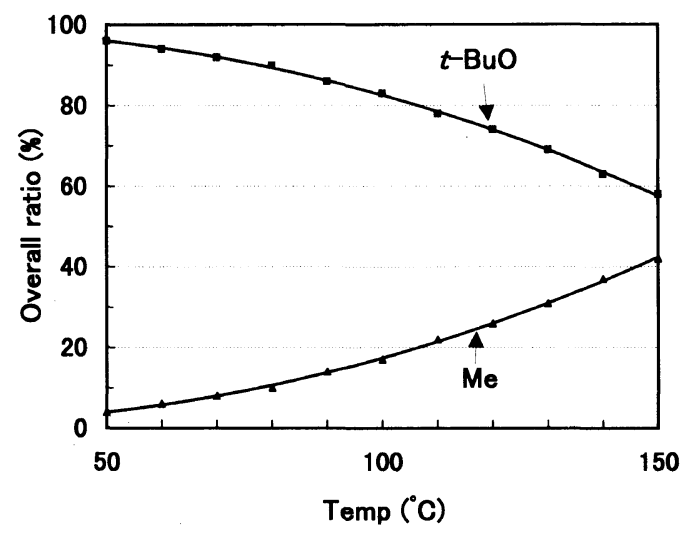

Figure 1. Temperature dependence of overall PS end group ratios of $t$-BuO/Me. See Table VII for details.

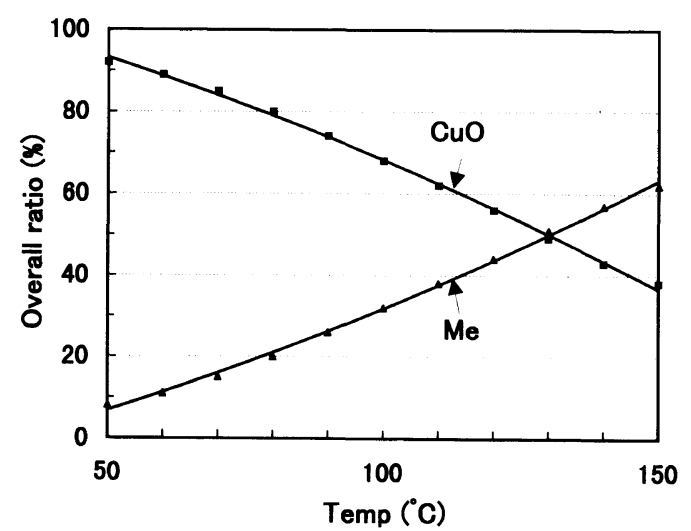

Figure 2. Temperature dependence of overall PS end group ratios of $\mathrm{CuO} / \mathrm{Me}$. See Table VIII for details.

$1-3$. For all cases, it is seen that the proportions of oxy end groups are quite high $(>80 \%)$ at temperatures below $80^{\circ} \mathrm{C}$ but they decrease with temperature.

$t$ - $\mathrm{BuO} \cdot$ and $\mathrm{CuO} \cdot$ give methyl radicals by their $\beta$ scission. Since $t$-BuO $\cdot$ has more methyl groups than $\mathrm{CuO} \cdot$, it was expected that $\beta$-scission of $t$ - $\mathrm{BuO} \cdot$ occurs

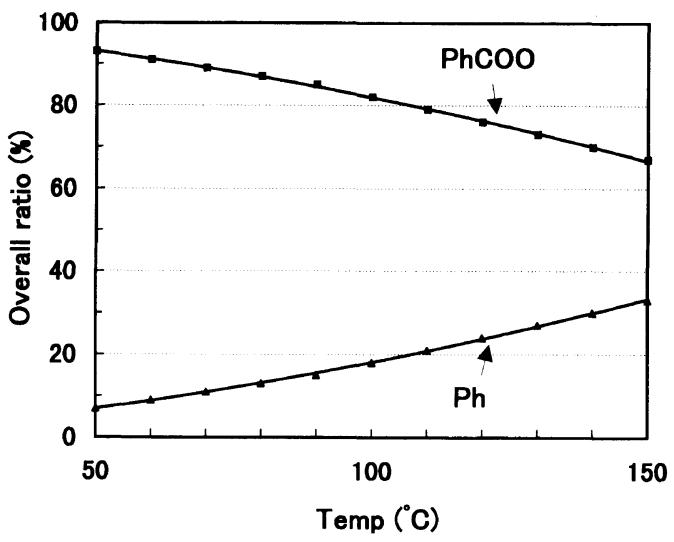

Figure 3. Temperature dependence of overall PS end group ratios of $\mathrm{PhCOO} / \mathrm{Ph}$. See Table IX for details.

faster than that of $\mathrm{CuO} \cdot$. However, the $k_{\mathrm{a}} / k_{\mathrm{d}}$ values for $\mathrm{CuO} \cdot$ are always smaller than those for $t$-BuO at the same temperature. Similar results were reported by Walling and Padwa. ${ }^{4}$ They studied competitive reactions between hydrogen abstraction by alkoxy radicals from cyclohexane $\left(k_{\text {abs }}\right)$ and their $\beta$-scission $\left(k_{\mathrm{d}}\right)$. The rate constant ratios, $k_{\mathrm{abs}} / k_{\mathrm{d}}$, for $\mathrm{CuO} \cdot$ were smaller than those for $t$-BuO $\cdot$. The unexpected smaller $k_{\mathrm{a}} / k_{\mathrm{d}}$ and $k_{\mathrm{abs}} / k_{\mathrm{d}}$ values for $\mathrm{CuO} \cdot$ can be reasonably explained by its faster $\beta$-scission since $\mathrm{CuO} \cdot$ affords acetophenone which is more stable than acetone from $t$-BuO $\cdot$. Alternatively, the slower bimolecular reactions (hydrogen abstraction or addition) of $\mathrm{CuO} \cdot$ due to steric and/or polar effects could lead to the smaller values. For details, information on the absolute rate constants will be required.

Solomon et al..$^{5-7}$ and Bevington et al..$^{8,9}$ reported the reactivity of oxy radicals with St. Based on the reported results, we calculated the end group ratios for initially formed polymers. As can be seen in Tables VII-IX, the present results are in fairly good agreement with those reported. This convinces us that the double bond reactivity of MSD is almost the same as that of styrene, and MSD is a suitable model compound of styrene. The present results will be quite useful for predicting and controlling peroxide-related end groups of polystyrene.

\section{REFERENCES}

1. Y. Watanabe, H. Ishigaki, H. Okada, and S. Suyama, Polym. J., 29, 366 (1997).

2. Y. Watanabe, H. Ishigaki, H. Okada, and S. Suyama, Polym. J., in press.

3. Y. Watanabe, H. Ishigaki, H. Okada, and S. Suyama, Chem. Lett., 1089 (1993); S. Suyama, H. Ishigaki, Y. Watanabe, and T. Nakamura, Polym. J., 27, 371 (1995); S. Suyama, H. Ishigaki, Y. Watanabe, and T. Nakamura, Polym. J., 27, 503 (1995).

4. C. Walling and A. Padwa, J. Am. Chem. Soc., 85, 1593 (1963).

5. P. G. Griffiths, E. Rizzardo, and D. H. Solomon, Tetrahedron Lett., 23, 1309 (1982).

6. E. Rizzardo, A. K. Serelis, and D. H. Solomon, Aust. J. Chem., 35, 2013 (1982)

7. G. Moad, E. Rizzardo, and D. H. Solomon, Makromol. Chem., Rapid Commun., 3, 533 (1982).

8. J. K. Allen and J. C. Bevington, Proc. Roy. Soc. A, 262, 271 (1961).

9. J. C. Bevington and J. Toole, J. Polym. Sci., 28, 413 (1958). 